MATEC Web of Conferences 13, 01004 (2014)

DOI: $10.1051 /$ matecconf/ 20141301004

(C) Owned by the authors, published by EDP Sciences, 2014

\title{
Modeling of Axial Spring Stiffness in Active Vibration Controlled Drilling
}

\author{
${ }^{a}$ William Pao, Fakhruldin M Hashim, Setyamartana Parman \\ Mechanical Engineering Department, Universiti Teknologi PETRONAS, Tronoh, Malaysia
}

\begin{abstract}
During drilling process, substantial amount of vibration and shock are induced to the drill string. Active vibration controlled drilling is introduced to reduce the vibration and increase the efficiency of drilling process. In this system, two main components that determine the damping coefficient are magnetorheological (MR) damper and spring assembly. Performance of vibration damping system is depending on the viscosity of MR fluid in the damper and spring constant of spring assembly. One of the key issues that are unclear from the design is the correlation between the axial spring stiffness configuration and the damping force which needs to be tuned actively. There has been lack of studies on how the viscosity of MR fluid on the active vibration damper affects the damping stiffness of the whole system. The objective of the project is to extract the correlations for the viscous damping coefficient, equivalent spring stiffness and power input to the system. Simplified vibration model is thus created using Simulink, together with experimental data fed from APS Technology's in-house team. Inputs of the simulation such as force exerted, mass of mandrel, spring constant and step time are based on the experimental data and can be adjusted to suit different experiments. By having the model, behavior of the system can be studied and analyzed. From the simulation, it is also observed that the relationship between damping coefficient and power input of the system is linear.
\end{abstract}

\section{Introduction}

During drilling process, substantial amount of vibration and shock are induced into the drill string. Drill string is under some heavy and complex dynamics loadings, caused by different sources such as rotation of drill bit, pumping drilling mud, and misalignment of drill string. By producing different state of stresses, these loads may result in excess vibrations and lead to failure of the drilling tools. Three forms of vibrations have been identified for drill string, namely are axial, torsional and lateral vibrations.

Magnetorheological (MR) damper in active vibration controlled drilling is introduced to improve the efficiency of drilling process. MR fluid contains magnetically polarizable micron-size particles dispersed in carrier liquid such as silicon oil [1]. Viscosity of MR fluid in the damper changes within milliseconds with the presence of magnetic field. Excessive downhole vibrations can be reduced by adjusting the magnetic field which MR fluid passes [2].

${ }^{\mathrm{a} C}$ Corresponding author: William.paokings@petronas.com.my

This is an Open Access article distributed under the terms of the Creative Commons Attribution License 2.0, which permits unrestricted use, distribution, and reproduction in any medium, provided the original work is properly cited. 
Without current

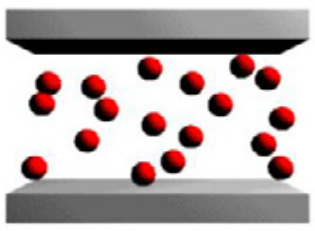

Current passing though

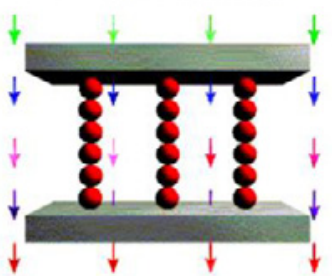

Figure 1. Behavior of MR Fluid

In active vibration control drilling, two main components that determine the damping stiffness are MR damper and spring assembly. Performance of vibration damping system is depending on the viscosity of MR fluid in the damper and spring constant of spring assembly [3-5]. One of the key issues that are unclear from the design is the correlation between the axial spring stiffness configuration and the damping force which needs to be tuned actively. There has been lack of studies on how the damping coefficient of MR damper on the active vibration damper affects the axial spring stiffness of the whole system.

The objectives of the research are to develop the correlation between the viscosity of magnetorheological (MR) fluid and axial spring stiffness and to investigate the relationship between the power input of the system and damping coefficient of the damper.

\section{Methodology}

Firstly, suitable simulation software is chosen to create the active vibration damping system. Next model is built according to the properties of vibration damping system. Simulation is ran with input data from APS technology such as force applied, mass of mandrel, spring constant and step time [3,4]. Simulation results are then compared with the experimental results. Simulation results are analyzed to improve the simulation model. Behavior of vibration damping system can be predicted and studied when the model is completely created.

Simulink Model. Simulink is a block-diagram-oriented computer package to simulate dynamic system. It can also interface with the MATLAB environment for maximum flexibility. Mathematical model can be created by using blocks from Simulink blocks library. Vibration controlled drilling system can be contructed by using the formula :

$$
\begin{gathered}
F=m \ddot{x}+c \dot{x}+k x \\
\ddot{x}=\frac{1}{m}(F-c \dot{x}-k x)
\end{gathered}
$$

From Figure 2 and 3, it can be seen that the Simulink model is constructed based on Equation 2. First the force applied on the mandrel and frictional force are added into the system. Next, loop of damping coefficient is created by multiplying with mass and velocity. Spring stiffness lookup table and feedback loop is created by the product of displacement and mass. Scope block is used to display the input with respect to the simulation time. Output block is used to extract the result data for further usage. Subsystem of frictional force is constructed based on Equation 3 and subsystem of damping coefficient based on Equation 4 where $\mathrm{P}$ is the percentage of power input. Equation 3 is the friction force extracted based on experimental data from APS technology while Equation 4 is the damping coefficient by trial and error method to fit the curves between simulation and experimental results, as shown in Figure 4. 


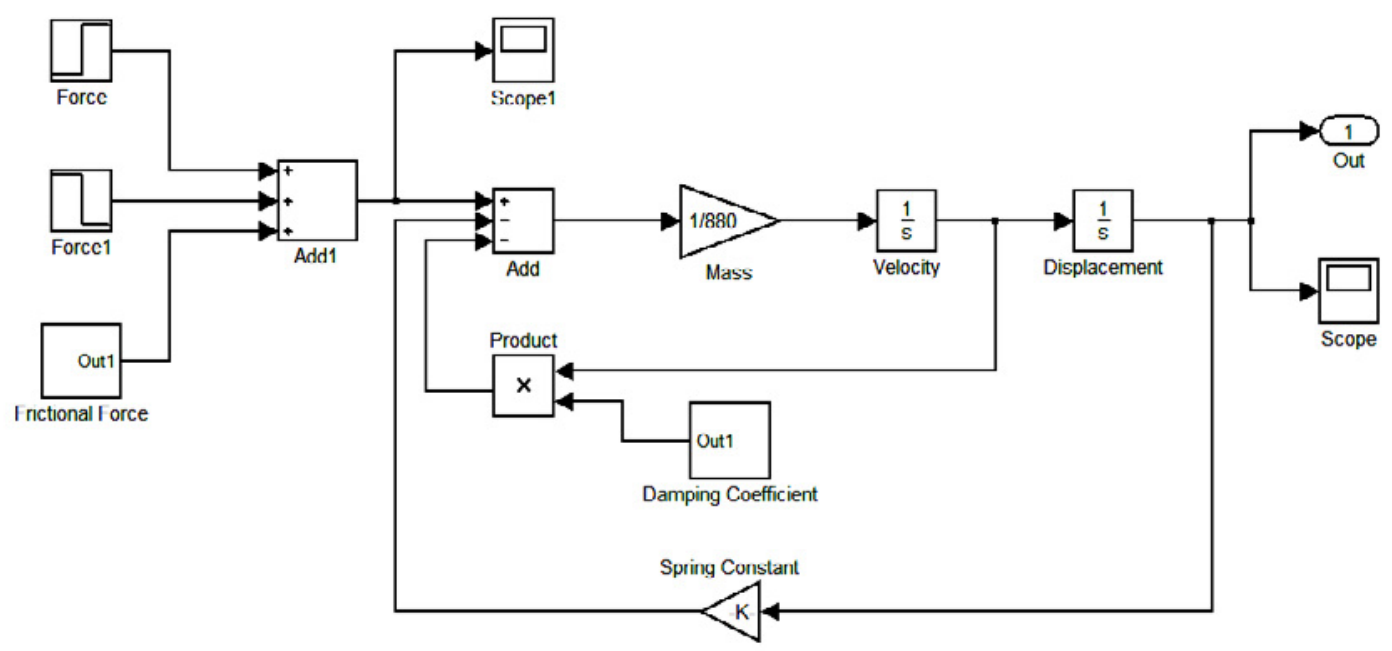

Figure 2. Simulation of force spring mass system using Simulink

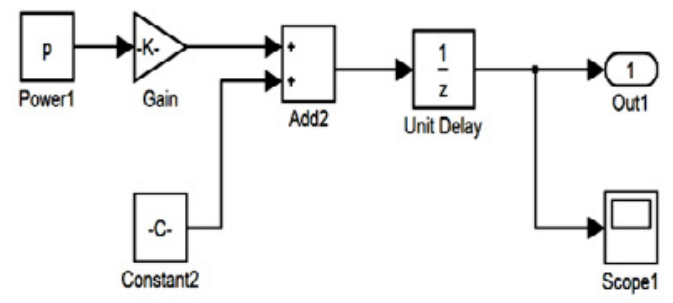

(a)

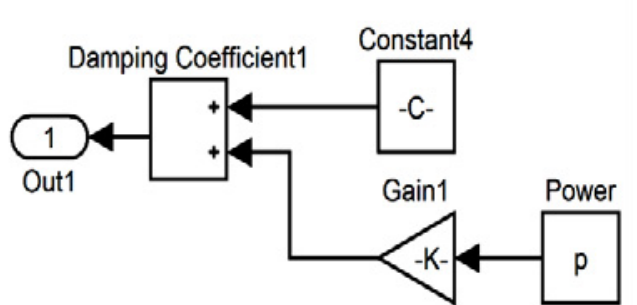

(b)

Figure 3. (a) Subsystem of frictional force (b) Subsystem of damping coefficient

$$
\begin{gathered}
F_{r}=6716.22 P+1924.65 \\
D=2297.3 P+741.9
\end{gathered}
$$




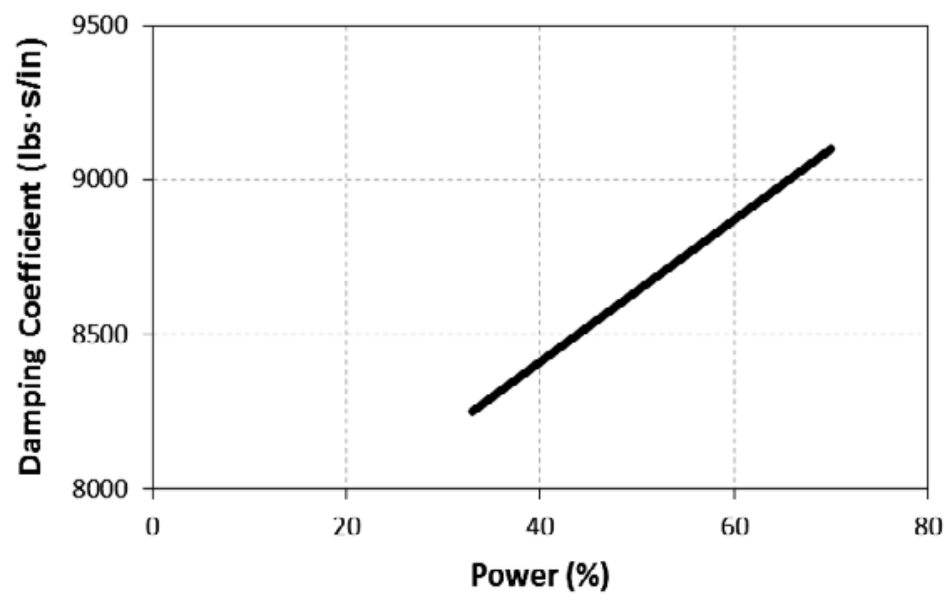

Figure 4. Graph of damping coefficient against power input

\section{Results and Discussion}

To test the validity of the simplified model, two experimental results were used to check the accuracy of the correlation. The experimental rig and data acquisition were done in APS Technology, Houston. Due to proprietary reasons, the Malaysian partner's access to the technical specification is limited to 'need-to-know' basis. In general, the initial applied force on mandrel is $49 \mathrm{klbf}$, mass of the mandrel is $880 \mathrm{lb}$, with an estimated initial spring stiffness of 16,565 lbf/in. The given percentage of power input is normalised by APS and no further specification was given. The displacement versus time data, acquired at the sampling rate of $1 \mathrm{~ms}$ was provided to the Malaysian partners. Two tests were conducted for $33 \%$ and $70 \%$ power input. The mandrel was released at $0.07 \mathrm{~s}$ for $33 \%$ power and $0.05 \mathrm{~s}$ for $70 \%$ power. The comparison of the experimental data and simulink model is shown in Figure 5. Initial displacement of the system is 3 " while step time of simulation is $4 \mathrm{~s}$. Frictional force occured once the mandrel is released.

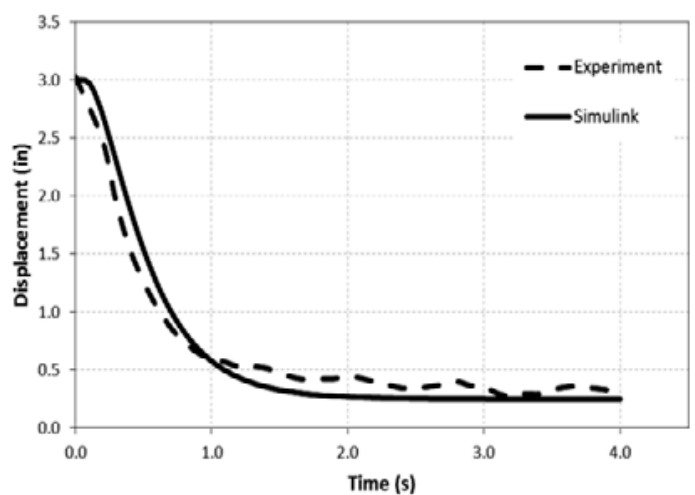

(a)

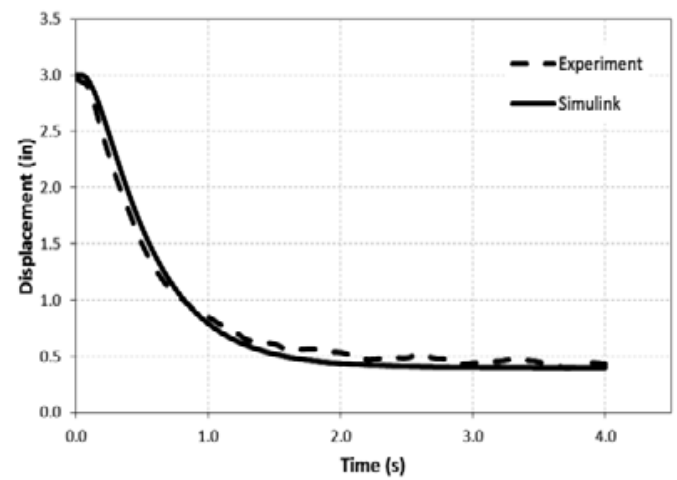

(b)

Figure 5. (a) Displacement graph of power 33\% (b) Displacement graph of power 70\%

Figure 5 showed that the Simulink result, though dissimilar, are close to the proximity of the filtered experimental curves. The gradient of both curves are the most important indicator of the accuracy of the model. The experimental curve, especially for 33\% power input has a high level of fluctuation even though filters have been applied to remove noises. Figure 5 also showed that the present model is more accurate for higher power input compare to curve $33 \%$ power. 


\section{Conclusion}

Active Vibration Damping is an important technology that could provide substantial cost saving to Malaysia's oilfield drilling. The present paper describe the effort the extract correlations for AVD damping coefficients, spring stiffness and power input. This correlation could be used to tune the required damping, and the associated spring stiffness for a wide range of vibrational modes encountered in drilling.

\section{Acknowledgements}

The authors will like to acknowledge Mark Hutchinson from APS Technology and his team for the experimental data and assistance throughout the project. This project is funded by MOHE ERGS 0153AB-I16.

\section{References}

[1] Sapinski, B., Snamina, J. \& Romaszko, M. (2012) The Influence of A Magnetic Field on Vibration Parameters of A Cantilever Beam Filled with MR Fluid. Acta mechanica Et Automatic, 6(1)

[2] Walid H. E. (2002) Finite Element Analysis Based Modeling of Magneto Rheological Dampers. MSc thesis, Viginia Tech, US.

[3] Wassell $\mathrm{M}$ et al. (2012) U.S. Patent No. 8,087,476 B2. Washington, DC: U.S. Patent and Trademark

[4] Wassell M. et al. (2008) U.S. Patent No. US 2008/0315471. Washington, DC: U.S. Patent and Trademark

[5] Wassell M. E., Cobern M. E., Saheta V., Purwanto A., Cepeda M. (2008) Active Vibration Damper Improves Performance and Reduces Drilling Costs. World Oil, pp. 108-111 